\title{
Bases culturais para atribuição de gênero em Manxineru
}

\author{
Cultural basis for the masculine/feminine \\ gender distinction in Manxineru
}

\author{
Ana Suelly Arruda Câmara Cabral ${ }^{1}$ \\ Lucas Artur Manchinery² \\ Fábio Pereira Couto ${ }^{3}$ \\ Mariana Souza Samarra Manchineri ${ }^{4}$
}

\begin{abstract}
Resumo
Este artigo trata de motivações semânticas para a distinção de gênero masculino/feminino em Manxineru (Yine), família Aruák. Argumentamos que gênero é um traço distintivo dos referentes dos nomes, semanticamente transparente, marcado por meio de sufixos em nomes relativos a estágios da vida dos humanos e em nomes de relações de parentesco, mas cristalizado na forma fonológica de outros nomes. Mostramos que o gênero de um referente aciona concordância obrigatória por meio de afixos pessoais nos nomes em relação de posse e nos predicados verbais e adjetivais intransitivos, de acordo com o gênero do sujeito, e no caso dos verbos transitivos, com o gênero do objeto. Concluímos que a atribuição de gênero nesta língua é moldada na cultura e que, em vários casos, trata-se de atribuição de natureza puramente metafórica.

Palavras-chave: Gênero. Concordância. Bases culturais. Processos metafóricos. Família Aruák.
\end{abstract}
Abstract
This paper is about the semantic motivations for the masculine/feminine gender distinction in Manxineru (Yine), Aruák family. We argue that gender is a distinctive feature of the referents of nouns, semantically transparent, marked by means of suffixes in nouns referring either to stages of human beings or kin relations, although it appears crystallized in the phonological forms of other nouns. We show that the gender of a referent triggers obligatory agreement by means of personal affixes in nouns in possessive relations, and in nucleus of verbal and adjectival intransitive predicates, according to the gender of the subject, and in the case of transitive verbs, according to the gender of the object. We conclude that gender attribution in that language is modeled by the culture, and that in various cases it is of purely metaphoric nature.
Keywords: Gender. Agreement. Cultural basis. Metaphoric processes. Aruák familly.

\footnotetext{
${ }^{1}$ Laboratório de Línguas e Literaturas Indígenas da Universidade de Brasília (LALLI-UnB), Mestrado Profissional em Sustentabilidade junto a Povos e Terras Tradicionais (MESPT).

${ }^{2}$ Comissão Pró-Índio do Acre, MESPT, LALLI-UnB.

${ }^{3}$ Fundação Universidade de Rondônia (UNIR), LALLI-UnB.

${ }^{4}$ Comissão Pró-Índio do Acre, LALLI-UnB.
} 


\section{Introdução}

Gênero é uma das categorias gramaticais manifestadas de diferentes modos em diferentes línguas indígenas do Brasil e de áreas adjacentes, embora duas das expressões de gênero sejam as mais difundidas. Uma delas é a distinção entre fala masculina e feminina, a outra é a distinção de gênero masculino, feminino e neutro nos nomes com ou sem manifestações de concordância nos determinantes e nos núcleos de predicados de que são argumento. Tomemos, como exemplo, o Karajá, língua Jê Central, em que uma das formas por meio da qual as falas feminina e masculina são distinguidas é de natureza fonológica, realizando-se pela omissão sistemática das consoantes ? e $t \int$ na fala masculina (cf. Borges 1997; Rodrigues 2004; Ribeiro 2012). Em Xokléng, uma das duas línguas do sub-ramo Jê Meridional, recebem marca de gênero biológico nomes intrinsecamente femininos, o que condiciona a ocorrência da marca 'feminino' em nomes de animais à situação em que estes nomes se combinam com a palavra 'fềmea'. Nesta mesma língua, uma forma pronominal de terceira pessoa feminina $\partial i$, homófona e homônima da marca $\partial i$ 'feminino', contrasta com uma outra marca de terceira pessoa, a forma pronominal $t i$ 'masculino'(cf. Gakrán 2015).

Línguas Tupí-Guaraní do complexo Kawahíwa - Parintintín, Tenharin, Djiahúj, Uru-Ew-Waw-Waw, Juma, Amondáwa, Karipúna, Piripkúra, Apiaká e Kayabí -, todas distinguem gênero 'masculino' e 'feminino' de refrentes animados por meio de formas pronominais de terceira pessoa; e a língua Kayabi distingue, adicionalmente, formas pronominais masculinas e femininas de acordo com o sexo do falante. Em todas as línguas desse complexo manifesta-se um sistema de concordância nos núcleos de predicados transitivos e intransitivos. Outra língua Tupí-Guaraní, o Kamaiurá, distingue fala masculina de feminina por meio de partículas discursivas (Seki 2000; Paltu Kamaiurá 2015) e Awetí, fam. Awetí, tronco Tupí, distingue a fala masculina da fala feminina por meio de formas dêiticas - formas pronominais de primeira e de terceira pessoa, demonstrativos, advérbios e outros (Moserrat 1967; Drude 2002).

Campbell (2012) menciona outras línguas do Brasil em que gênero é uma categoria expressa, como as línguas da família Nambikwára e da família Karib. Outras famílias para as quais gênero gramatical tem sido reportado são línguas do Chaco (Tovar 1961; Akhenvald 2000; Campbell 2013).

De uma forma ou de outra, toda língua nativa do Brasil faz, em princípio, alguma distinção de gênero biológico. Em línguas Aruák, nomes, determinantes destes e núcleos de predicados verbais e adjetivais dos quais são argumento recebem marcas distintivas de gênero de terceira pessoa. Entretanto, nessas línguas, quando o referente de um nome ou pronome não é um ser humano, é consenso entre os estudiosos que não há, em princípio, motivação semântica evidente para a marcação de gênero. Facundes (2000: 223) reporta para o 
Apurinã que todos os nomes nessa língua, inclusive os derivados de outras categorias são ou masculinos ou femininos, pois todos envolvem um formativo correferencial encontrado no determinante ou no predicado. Mas ressalta que a maioria dos nomes que não diferenciam sexo não são marcados para gênero, e que à maioria destes é atribuído o gênero masculino, como nomes para 'canoa', 'árvore', 'lenha', etc. (p. 224-225). Ramirez (2001:174) observa que em Baníwa 'Certos nomes dependentes têm sempre uma marca de gênero, $+l i$ 'masculino' e + ${ }^{\circ}$ 'feminino', seguindo a raiz. Isto se verifica especialmente nos termos de parentesco'. Mas, deixa claro que a distinção de gênero só é clara nos termos relativos a humanos e que o mesmo é válido para as marcas pessoais que concordam com o gênero dos referentes nominais. ${ }^{5}$

Quanto à distinção de gênero em Manxineru (Yine), também conhecida como Mashco-Piro, Hanson (2010) afirma que não são encontrados sinais óbvios de motivação semântica para a expressão de gênero nessa língua.

For human and other sex-differentiable referents, grammatical gender is consistent with natural gender. For all other referents the basis of gender assignment is not as obvious, though certain tendencies can be observed: for example, abstract nouns strongly tend to be masculine, as do larger animals and snakes; reptiles, insects, small animals and birds tend to be feminine. (Hanson 2010:96)

Neste artigo argumentamos que há, sim, motivações semânticas na atribuição de gênero masculino e feminino em Manxineru. Diferentemente das análises precedentes trazemos dados que sustentam a existência de claras motivações semânticas e culturais para a distinção de nomes masculinos e femininos nessa língua, desde o léxico. Mostramos que, na sintaxe, a concordância de gênero é obrigatória e se dá por meio de afixos pessoais nos nomes em relação de posse e nos predicados verbais e adjetivais. Marcas de gênero são também encontradas em nomes relativos a estágios da vida dos humanos e nomes de relações de parentesco. Concluímos que a atribuição de gênero nesta língua é moldada pela cultura e que, em vários casos trata-se de atribuição de natureza puramente metafórica.

Os resultados deste estudo também contradizem a visão de que na região do Purus, que corresponde ao encontro do Peru, da Bolívia e do Brasil, gênero

\footnotetext{
${ }^{5}$ Para Ramirez (2001: 467), "a existência de três sufixos formativos em Baniwa-Curripaco

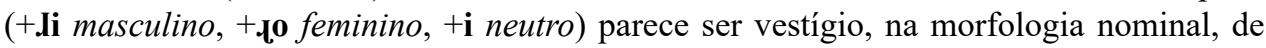
um antigo sistema de marcas de gênero ou de classificadores da família arawak". Estes vestígios poderiam mostrar que o proto-arawak possuía 3 gêneros (o masculino, o feminino e o neutro). De fato, existem línguas arawak com 3 gêneros, como o Palikur e o Ignaciano. No entanto, este sistema perdeu todo o seu significado para os falantes atuais da língua baniwa-curripaco.
} 
gramatical não é semanticamente transparente, como proposto por Dixon e Akhenvald (1999:10). ${ }^{6}$

$\mathrm{Na}$ seção 2 deste estudo descrevemos aspectos formais da expressão de gênero em Manxineru. Na seção 3 argumentamos em favor das bases semânticas da classificação dos referentes dos nomes nessa língua em masculinos ou femininos. Finalmente, apresentamos algumas considerações finais sobre as bases semânticas e culturais na atribuição de gênero em Manxineru.

\section{A expressão de gênero em Manxineru ${ }^{7}$}

Em Manxineru, todo nome, desde o léxico, é distinto quanto ao gênero masculino ou feminino, e como ocorre na maioria das línguas Aruák, aos nomes cujos referentes são humanos, associam-se sufixos de gênero masculino ou feminino, como por exemplo yine-rit 'gente, pessoa (referente homem)' yine-ro 'gente, pessoa (referente mulher)'. Entretanto, há alguns nomes cuja distinção biológica do referente masculino ou feminino não se dá por meio sufixação de marcas de gênero, mas é identificada, nas suas respectivas formas fonológicas, uma sequência de sons que teria correspondido, no passado, à uma distinção de gênero masculino/feminino(/neutro), por meio de sufixos, como são os casos de nomes cujos referentes são estágios da vida de humanos, por exemplo, makliç̧i 'menino, rapaz' (masculino) e makloci 'menina, moça' (feminino) ${ }^{8}$. Nomes de certos animais também apresentam distinção de masculino e feminino, mas outros animais e referentes não humanos possuem, em princípio um único gênero, masculino ou feminino. Entretanto, a relação referente/gênero nesses nomes, aparentemente arbitrária, é, como será demonstrado adiante, semanticamente e culturalmente motivada.

Manxineru também apresenta, como na maioria das línguas Aruák, um sistema de concordância com o gênero dos referentes dos nomes, presente nas formas de demonstrativos, nas formas verbais transitivas e intransitivas ativas por meio de prefixos e nos núcleos de predicados adjetivais e de predicados verbais transitivos, por meio de sufixos.

No quadro seguinte reunimos as marcas de gênero do Manxineru que se combinam com nomes, adjetivos e verbos.

\footnotetext{
${ }^{6}$ Os dados utilizados são da variante falada no Brasil, na Terra Indígena Mamoadate, no Acre. ${ }^{7}$ Abreviaturas: ABs: Absoluto; DIM: Diminutivo; F: Feminino; INV.: Invisível; M: Masculino; NEG: Negação; PL: Plural; PRIV: Privativo; 1: Primeira pessoa; 2: Segunda pessoa; 3M: Terceira pessoa masculina; 3F: Terceira pessoa feminina.

${ }^{8}$ Talvez uma distinção tridimensional, que teria incluído o gênero neutro, haja vista uma quantidade de nomes que não apresenta vestígios de marca nem feminina nem masculina.
} 


\begin{tabular}{|l|c|c|c|c|}
\hline \multicolumn{1}{|c|}{ BASES LEXICAIS } & $\begin{array}{c}\text { STATUS } \\
\text { GRAMATICAL } \\
\text { DOS AFIXOS }\end{array}$ & \multicolumn{2}{|c|}{$\begin{array}{c}\text { AFIXOS } \\
\text { DISTINTIVOS DE } \\
\text { GÊNERO }\end{array}$} & \\
\hline & & $3 \mathrm{msg}$ & $3 \mathrm{fsg}$ & $3 \mathrm{pl}$ \\
\hline $\begin{array}{l}\text { Nomes, adjetivos, sujeito } \\
\text { de predicados adjetivais, } \\
\text { objeto de verbos } \\
\text { transitivos, advérbios }\end{array}$ & SUFIXOS & - ri & - -ro & -na \\
\hline $\begin{array}{l}\text { Sujeito de verbos } \\
\text { transitivos e intransitivos } \\
\text { ativos }\end{array}$ & PREFIXOS & $r-, \varnothing-, t-$ & $t-, t o-$ & $r-, \varnothing-, h i-$ \\
\hline
\end{tabular}

Esse quadro mostra que as marcas de gênero dos nomes são as mesmas que ocorrem nos adjetivos, nos demonstrativos, nos advérbios e nos núcleos de predicados verbais transitivos, neste caso concordando com o objeto, e em predicados adjetivais concordando com o sujeito. Já o sujeito de verbos transitivos e de verbos intransitivos ativos é marcado por meio de prefixos.

\subsection{Marcas de gênero nos nomes}

Nomes de referentes humanos e genéricos, quando individualizados são marcados para gênero:

$$
\begin{array}{ll}
\begin{array}{ll}
\text { yine } \\
\text { yine-ri } \\
\text { yine-ro }
\end{array} & \begin{array}{l}
\text { 'gente', 'pessoa' } \\
\text { 'gente, pessoa (referente homem)' }
\end{array} \\
\begin{array}{ll}
\text { pane-ri } \\
\text { pane-ro }
\end{array} & \text { 'nação (referente homem)' } \\
& \text { 'nação (referente mulher)' } \\
\text { nahkan-ri } & \text { 'inimigo homem' } \\
\text { nahkan-ro } & \text { 'inimigo mulher' }
\end{array}
$$

O mesmo ocorre com nomes de certos animais:

$$
\begin{array}{ll}
\text { mhenokli } & \text { 'jaguar macho' } \\
\text { mhenoklo } & \text { 'jaguar fêmea' }
\end{array}
$$

Como é amplamente conhecido pela literatura relevante, as línguas Aruák distinguem nomes de referentes alienáveis de nomes de referentes inalienáveis. 
Os primeiros ao entrarem em uma relação de posse requerem um mediador, que em Manxineru tem os alomorfes -te, -ne e -re. Por outro lado, os nomes de referentes inalienáveis entram em relação de posse sem nenhuma marca mediadora dessa relação, e como são inerentemente relativos, para ocorrerem em função absoluta requerem um mediador, que tem a forma $-t \int i$. Os exemplos seguintes mostram a distinção de gênero por meio de marcas pessoais nos dois tipos de nomes em relação de posse.

'coração'

$\begin{array}{ll}\text { n-açi } & \text { 'meu coração' } \\ \text { p-açi } & \text { 'teu coração' } \\ \text { w-açi } & \text { 'nosso coração' } \\ \text { r-açi } & \text { 'coração dele' } \\ \text { t-açi } & \text { 'coração dela' } \\ \text { h-açi } & \text { 'coração de vocês' } \\ \text { h-aç-t } f i & \text { 'coração (absoluto)' }\end{array}$

'algodão'

$\begin{array}{ll}\text { n-waphũ-te } & \text { 'meu algodão' } \\ \text { p-waphũ-te } & \text { 'teu algodão' } \\ \text { w-aphũ-te } & \text { 'algodão de nós' } \\ \text { r-waphũ-te } & \text { 'algodão dele' } \\ \text { t-waphũ-te } & \text { 'algodão dela' } \\ \text { h-waphũ-te } & \text { 'algodão de vocês' } \\ \text { wa:phũ } & \text { 'algodão' }\end{array}$

'peixe'
n-fim-ne
'meu peixe'
p-fim-ne
'teu peixe'
u-fim-ne
'peixe de nós'
r-fim-ne
'peixe dele'
t-fim-ne
'peixe dela'
h-fim-ne
'peixe de vocês'
Jima 'peixe' 
'carne'

$\begin{array}{ll}\text { n-nika-le } & \text { 'minha carne de caça' } \\ \text { p-nika-le } & \text { 'tua carne de caça' } \\ \text { u-nika-le } & \text { 'carne de caça de nós' } \\ \text { ri-nika-le } & \text { 'carne de caça dele' } \\ \text { to- nika-le } & \text { 'carne de caça dela' } \\ \text { ha-nika-le } & \text { 'carne de caça de vocês' } \\ \text { nikali } & \text { 'carne de caça' }\end{array}$

\subsection{Gênero nos demonstrativos}

Manxineru distingue nos seus demonstrativos três graus de distância do que é indicado com respeito ao centro dêitico (o falante): proximal, distal e remoto. Proximal e distal singulares distinguem masculino e feminino. Apenas o remoto (invisível) e as formas plurais não apresentam distinção de gênero).

\begin{tabular}{|c|c|c|c|c|}
\hline \multicolumn{2}{|l|}{} & \multicolumn{2}{|c|}{ singular } & Plural \\
\cline { 3 - 5 } \multicolumn{2}{|c|}{} & masculino & feminino & \\
\hline \multirow{2}{*}{ PROXIMAL } & & & \\
\cline { 3 - 5 } & \multirow{2}{*}{ VISÍVEL } & tje & $t w i$ & $n j i$ \\
\cline { 3 - 5 } DISTAL & & tiçra & toçra & naçra \\
\hline REMOTO & \multirow{2}{*}{ INVISÍVEL } & \multicolumn{2}{|c|}{ tika } & waçra \\
\hline
\end{tabular}

As formas contrastam, assim, quanto ao gênero, quanto à distância e quanto à visibilidade do que é indicado em relação ao centro dêitico. Embora as marcas de gênero nessas formas não sejam sincronicamente segmentáveis, podem ser claramente identificados vestígios de marcas de gênero nas sequências fonológicas to, correspondente ao sufixo 'feminino' -to e $t \dot{t}$, correspondente ao sufixo - $t \dot{t}$ 'masculino', de cada forma do proximal e do distal. Já nas formas do proximal, infere-se que houve historicamente a silabificação das vogais $\dot{t} \mathrm{e} o$, respectivamente diante de $e$ e $\dot{t}$.

Exemplos de concordância de gênero nos demonstrativos:

$$
\begin{aligned}
& \text { xye pan-tshi nu-kojiru-nu } \\
& \text { esta casa-ABS 1-irmão da mãe-3M } \\
& \text { 'esta casa é do meu tio materno' }
\end{aligned}
$$


twi kanawa-ts-ro

esta canoa-grande-3F

'esta canoa é grande'

tojra kanawa hi ts-ro

aquela canoa NEG grande-3F

'aquela canoa é pequena'

tiçra pan-tshi nu-kojiru-nu

aquele casa-ABS 1-irmão da mãe-3M

'aquela casa é do meu tio materno'

tuka pan-tshi nu-kojiru-nu

aquelele.inv casa-ABS 1-irmão da mãe-3M

'aquela(inv.) casa é do meu tio materno'

tuka kanawa hi ts-ro

aquela canoa NEG grande-FEM

'aquela(inv.) canoa é pequena'

najra kanawa-ne hi ts-ro

aquelas canoa-PL NEG grande-3M

'aquelas canoas são pequenas'

najra pan-tshi-ne nu-kojiru-nu

aquele.INV casa-ABS-PL 1-irmão.da.mãe-3M

'aquela (inv.) casas são do meu tio materno'

\subsection{Adjetivos}

Adjetivos concordam em gênero com o referente dos nomes que modificam:

kihle-ro mte-ro

bonito-3F menina-3F

'menina bonita'

tse-ro-wna-tsh-ro

sitfo

Alto-3F-fino e alto-gente-3F mulher

'mulher alta' 


$$
\begin{aligned}
& \text { bihle-ro mte-ro } \\
& \text { Bonito-3F menina } \\
& \text { 'a menina é bonita' } \\
& \text { çeçi mpikakle-ti } \\
& \text { homem coragem-3M } \\
& \text { 'o homem é corajoso' }
\end{aligned}
$$

Adjetivos, quando núcleo de predicados, se combinam com sufixos pessoais que marcam a concordância com o sujeito, -rit 'masculino'e -ro 'feminino'. E quando um adjetivo é marcado pelo privativo $m a-$, os alomorfes dos sufixos de concordância são - $t \dot{t}$ 'masculino' e -to 'feminino', com algumas poucas exceções.

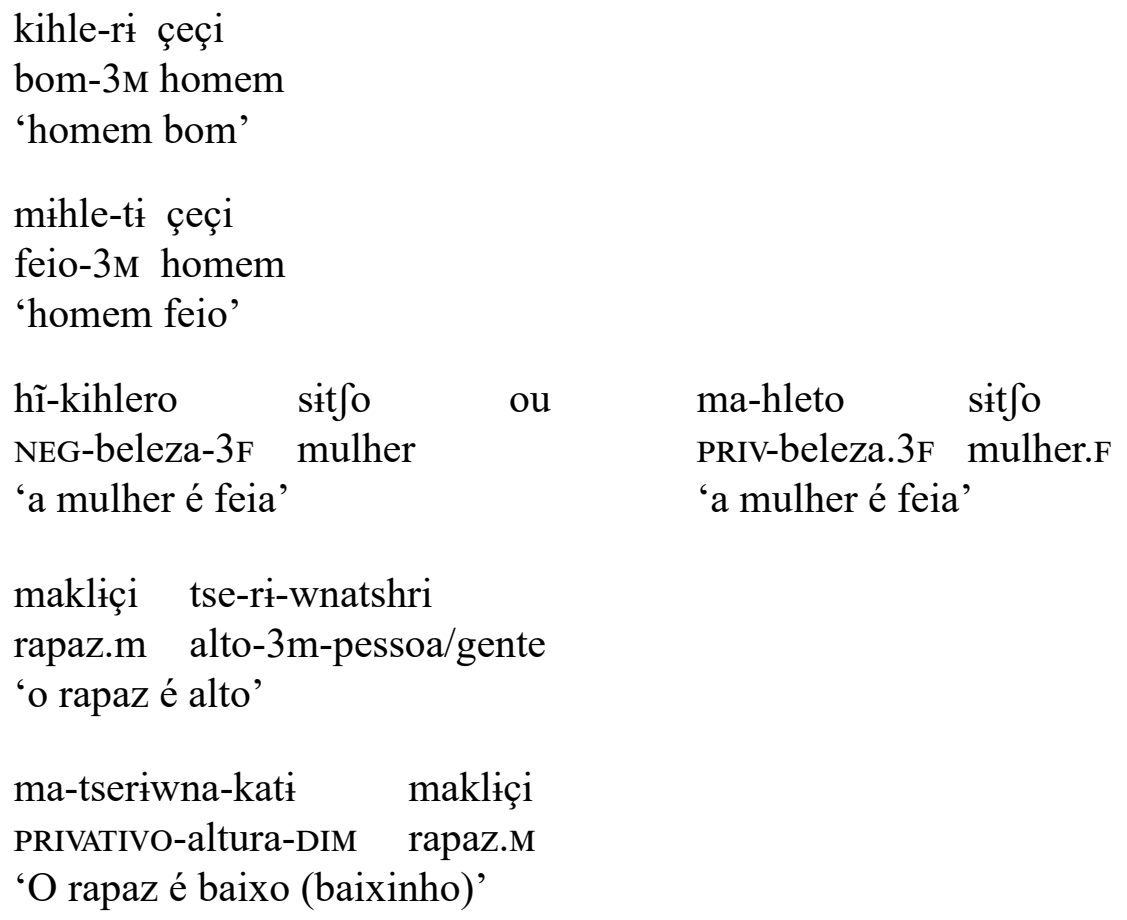

\subsection{Marcas de gênero nos verbos}

As marcas pessoais nos verbos Manxineru distribuem-se de acordo com um subtipo de alinhamento ativo/estativo. Um conjunto de formas pessoais funciona tanto como sujeito de predicados adjetivais quanto como objeto de verbos transitivos, e em ambos os casos referentes são experienciadores, como ocorre na maioria das línguas da família. Outro conjunto marca o sujeito de 
predicados verbais transitivos e intransitivos ativos. A cisão está, portanto, na codificação do sujeito dos dois tipos de predicados. As formas dos prefixos de terceira pessoa que se combinam com predicados ativos e dos sufixos de $3 \mathrm{a}$ pessoa que se combinam com predicados intransitivos estativos, apresentados no quadro 1 e repetidos no quadro seguinte, concordam com o gênero do referente do argumento que codificam.

\begin{tabular}{|l|c|c|}
\hline & $3 \mathrm{msg}$ & $3 \mathrm{fsg}$ \\
\hline sufixos absolutivos & $-r \dot{t}$ & $-r o$ \\
\hline prefixos nominativos & $r-, r \dot{i}-, t-$ & $t-, t o-$ \\
\hline
\end{tabular}

Alinhamento nominativo

Predicados intransitivos ativos:

ri-çrika

3M-cair

'ele caiu'

ti-çrika

3F-cair

'ela caiu'

Predicados transitivos:

Jima çimli-ro h९-nika (peixe genérico é feminino)

peixe assado-3F 3M-comer

'ele come peixe assado'

Jima çimli-ro to-nika

peixe assado-3F 3F-comer

'ela comeu peixe assado'

Predicados intransitivos adjetivais:

'wale kihle-ri'

$3 \mathrm{M}$ beleza-3m

'ele é bonito'

'wala kihle-ro'

3F beleza-3F

'ela é bonita' 


\section{Bases culturais na atribuição de gênero em Manxineru}

A língua Manxineru nos mostra que todas as entidades são classificadas em um ou outro gênero e que essa classificação é culturalmente motivada.

Para um olhar estrangeiro é difícil entender que existe uma motivação semântica na atribuição de gênero em Manxineru. Afinal, afora a nítida distinção de gênero masculino e feminino relativa a seres humanos e a certos animais, não há, à primeira vista, nenhum critério semântico que possa explicar o fato de que aves da família Psittacidae, como araras, papagaios periquitos, paracanãs, tuins, jandáias, entre outras, sejam femininas e que o jacu, o pica-pau, os urubus e gaviões sejam masculinos; e como entender que aranhas são femininas e que entre as formigas há as que são masculinas, como a tucandeira, mas outras, são femininas? E também pode parecer estranho o fato de que o purake e o cascudo sejam masculinos, enquanto a maioria dos peixes é feminina, assim como quase tudo o mais que se encontra na água. E por que a anta é feminina e a onça masculina? Se para os não Manxineru o pertencimento de um referente de um nome a um gênero ou outro é ou parece ser arbitrário, para os Manxineru o gênero que se atribui aos seres não humanos - elementos da natureza, animais, plantas e objetos pessoais - têm sempre uma explicação cultural. No que segue, argumentamos em favor da existência de bases semântico-culturais para a classificação dos seres em Manxineru em masculinos ou femininos.

\subsection{Ouvindo os mais velhos}

A pesquisa que resultou neste artigo incluiu a fundamental colaboração de alguns sábios Manxineru que explicaram na sua própria língua a Lucas Artur Brasil Manxineru, um dos autores deste trabalho, as relações entre perfis comportamentais ou características dos seres que culturalmente são associados ou à natureza feminina ou à masculina, assim como ensinaram que o passado imemorial traz explicações para o pertencimento de certos animais à classe masculina ou feminina. A noção de gênero para os Manxineru lastreia-se, assim, em um conceito biológico de 'ser macho' em oposição a 'ser fêmea', característica inerente dos humanos que se estende aos demais seres por meio de processos analógicos metafóricos.

Exemplos de marcação de gênero em nomes relativos a humanos:

$\begin{array}{ll}\text { 1) çeçi } & \text { 'homem' } \\ \text { netali çeçi } & \text { 'eu vi o homem' } \\ \text { netali } & \text { 'eu o(homem) vi' } \\ \text { kihleri çeçi } & \text { 'homem bonito' } \\ \text { çeçi mfinikaniti } & \text { 'homem ruim, homem mau' } \\ \text { sati çeçi } & \text { 'um homem' }\end{array}$




$\begin{array}{ll}\text { 2) sitfo } & \text { 'mulher' } \\ \text { netalo sitfo } & \text { 'eu vi a mulher' } \\ \text { metalo } & \text { 'eu a(mulher) vi' } \\ \text { kihlero sitfo } & \text { 'mulher bonita' } \\ \text { sitfo mfinikanito } & \text { 'mulher ruim, mulher má' } \\ \text { sato sitfo } & \text { 'uma mulher' }\end{array}$

Segundo o modo de ver o mundo dos Manxineru, os gêneros feminino e masculino associam-se respectivamente aos mundos aquático e não aquático. O que pertence à água ou que tem uma relação direta com ela é, em princípio, feminino; já o que é não aquático, o que é da terra e do céu, é, em princípio, associado ao gênero masculino. Os guardiões das águas, vivem nas fontes dos lagos e dos rios, são eles o kçioçiri 'jacaré açu', a mapxuri 'sucuri' ou 'cobra grande', o Pitsoti 'purakê' e a hpuyo 'arraia'. O guardião mais importante é o jacaré que vigia a água e o que está dentro dela, protegendo-a. A sucuri cuida de todos os peixes e forma os poços dos rios e igarapés, que servem para acasalamento dos seres aquáticos e sua consequente continuidade. A arraia além de cavar os poços, cuida deles, não permitindo que os humanos estraguem o peixe e sujem a água. A natureza puxa para dentro dos poços os que tentam desrespeitar o equilíbrio desses lugares sagrados onde se concentram a riqueza da vida aquática que tem repercussões na vida fora da água. Já o purakê, é o que tem o papel de macho, comandando a água e protegendo-a com a sua arma natural, a eletricidade. Com exceção do purakê os outros três guardiões são do gênero feminino.

Sendo a água, símbolo da vida, é mãe, pertencente ao gênero feminino e, em princípio, o que está associado a ela é também feminino. Dessa forma, a maioria dos peixes, crustáceos e demais elementos da água são femininos, enquanto que insetos, pássaros, bichos de couro, elementos da natureza não aquáticos, incluindo o céu e a lua são masculinos. O urubu, por exemplo, não é da água, assim pertence ao gênero masculino, como o gavião real, o gavião do meio dia (que já foi gente um dia), o jacu, o pica-pau, entre muitos outros. Alguns exemplos são:

$\begin{array}{ll}\text { 3) 'mawli' } & \text { 'urubu' } \\ \text { netili mawli } & \text { 'eu vi o urubu' } \\ \text { netili } & \text { 'eu o(urubu) vi' } \\ \text { kihleri mawli } & \text { 'urubu bonito' } \\ \text { tsrirı mawli } & \text { 'urubu grande' } \\ \text { mtseriti mawli } & \text { 'urubu pequeno' }\end{array}$




$\begin{array}{ll}\text { ksaçiri mawli } & \text { 'urubu preto' } \\ \text { klatali mawli } & \text { 'urubu branco' } \\ \text { kserili mawli } & \text { 'urubu vermelho' } \\ \text { sati mawli } & \text { 'um urubu' }\end{array}$

Entretanto, diferentes fatores culturais interferem na classificação dos seres em um ou outro gênero. Por exemplo, a arara, embora seja um ser não aquático é do gênero feminino porque fala muito, fala como mulher, dizem os Manxineru.

$\begin{array}{ll}\text { 4) pamolo } & \text { 'arara' } \\ \text { netalo pamolo } & \text { 'eu vi a arara' } \\ \text { netalo } & \text { 'eu a(arara) vi' } \\ \text { kihlero pamolo } & \text { 'arara bonita' } \\ \text { tsrolo pamolo } & \text { 'arara grande' } \\ \text { mtseroto pamalo } & \text { 'arara pequena' } \\ \text { ksaçiro } & \text { 'arara preta' } \\ \text { klatalo } & \text { 'arara branca' } \\ \text { kserolo } & \text { 'arara vermelha' } \\ \text { sato pamolo } & \text { 'uma arara' }\end{array}$

Já o bodó é masculino, embora seja da água, porque tem casco duro e rói madeira, uma atividade que se associa ao trabalho de macho, derrubador e cortador de pau.

$\begin{array}{ll}\text { 5) ratfifiri } & \text { 'bodó' } \\ \text { netali ratfifiri } & \text { 'eu vi o bodó' } \\ \text { netali } & \text { 'eu o (bodó) vi' } \\ \text { kihleri ratfifiri } & \text { 'bodó bonito' } \\ \text { tsrili ratfifiri } & \text { 'bodó grande' } \\ \text { ksaçiri ratfifiri } & \text { 'bodó preto' } \\ \text { klatali ratfifiri } & \text { 'bodó branco' } \\ \text { kseroli ratfifiri } & \text { 'bodó vermelho' } \\ \text { sati ratfiri } & \text { 'um bodó' }\end{array}$

Formigas cujo comportamento se associa ao macho, são classificadas quanto ao gênero como masculinas. Uma das exceções é a formiga de roça (do gênero 
Attas), pois os machos (Bitus) pertencem ao gênero masculino, já as aladas, iças ou tanajuras, são do gênero feminino. Note-se que esta classificação corresponde à classificação científica de machos e fêmeas nessa família. Por outro lado, as tucandeiras (Paraponera clavata) como fazem tanto o papel masculino quanto o feminino podem ser tanto tratadas como do gênero masculino, quando do gênero feminino. Quando o que está em relevo é a sua picada, ela é tratada como pertencente ao gênero masculino, mas quando nos referimos ao buraco da tucandeira, ela é tratada como pertencente ao gênero feminino:

a) manehe

netalo/netali manehe netalo/netali kihleri/kihlero manehe tsrili/tsrolo manehe mtseroto/mtseriti manehe sato/sati manehe 'tucandeira'

'eu vi a/o tucandeira' 'eu a/o(tucandeira) vi' 'tucandeira bonita/bonito' 'tucandeira grande' 'tucandeira pequena/pequeno' 'uma/um tucandeira'

As formigas que são classificadas como femininas são as que fazem trabalho mais leve, as que ficam mais no formigueiro, como a tracoá.
a) katfotalo
'tracoá'
netalo Katfotalo
'eu vi a tracoá'
netalo
'eu a(tracoá) vi'
kihlero Kat fotalo
'a tracoá é bonita'
tsrolo Katfotalo
'a tracoá e grande'
mtseroto Katfotalo
'tracoá pequena/pequeno'
sato Katfotalo
'uma/um tracoá'

Todas as formigas classificadas como masculinas são as que fazem trabalho pesado e também defendem o território.
b) katfitfi
'formiga de roça (bitus)'
netali kat $\int i t f i$
'eu vi a formiga de roça'
netali
'eu a(formiga de roça) vi'
kihleri katfitfi
'formiga da roça bonito'
tsrili kat $\int i t \int i$
'formiga da roça grande'
mtseriti
'formiga da roça pequeno'
sati katfitfi
'uma/um formiga da roça' 
Todas as abelhas são femininas porque produzem mel, como as mulheres que produzem o leite materno e preparam caiçuma.

a) mihi

netalo mihi

netalo

kihlero mihi

tsrolo mihi

mtseroto mihi

sato mihi

b) poleçiro

netalo poleçiro

netalo

kihlero poleçiro

tsrolo poleçiro

mtseroto poleçiro

sato poleçiro

c) kamotolo

netalo kamotolo

netalo

kihlero kamotolo

tsrolo kamotolo

mtseroto kamotolo

sato

d) kajonalo

netalo kajonalo

netalo

kihlero kajonalo

tsrolo kajonalo

mtseroto kajonalo

kinaçimeçi

netalo kinaçimeçi 'abelha preta'

'eu vi a abelha preta'

'eu a(abelha preta) vi'

'abelha bonita'

'abelha preta grande'

'abelha preta pequena'

'uma abelha preta'

'esp. de abelha'

'eu via a poleçiro'

'eu a(poleçiro) vi'

'poleçiro kihlero'

'poleçiro grande'

'poleçiro pequena'

'um poleçiro'

'esp. de abelha'

“eu vi a kamotolo'

'eu a(kamotolo) vi'

'kamotolo bonita'

'kamotolo grande'

'kamotolo pequena'

'abelha jataí'

'eu vi a abelha jataí'

'eu a(abelha jataí) vi'

'abelha jataí bonita'

'abelha jataí grande'

'abelha jataí pequena'

'esp. de abelha'

'eu vi a kinaçimeçi' 


$\begin{array}{ll}\text { netalo } & \text { 'eu a(kinaçimeçi) vi' } \\ \text { kihlero kinaçimeçi } & \text { 'kinaçimeçi bonita' } \\ \text { tsrolo kinaçimeçi } & \text { 'kinaçimeçi grande' } \\ \text { mtseroto kinaçimeçi } & \text { 'kinaçimeçi pequena' } \\ \text { sato kinaçimeçi } & \text { 'uma sato' }\end{array}$

Já os maribondos são, em princípio, machos, porque têm ferrão e, assim, associam-se ao gênero masculino.
a) sane
'maribondo'
netali sane
'eu vi o maribondo'
netali
'eu o (maribondo) vi'
kihleri sane
'maribondo bonito'
tsrili sane
'maribondo grande'
mtseriti sane
'maribondo pequeno'
sati sane'
'um maribondo'
b) tfipirisane
'tapium (esp. de maribondo)'
'eu vi o tapium'
'eu o(tapium) vi'
'tapium bonito'
'tapium grande'
'tapium pequeno'
'um tapium'
netali tfipirisane
netali
kihleri tfipirisane
tsrili t tipirisane
mtseriti tfipirisane
sati $\mathrm{t}$ fipirisane
c) kinsane
'caba vermelha'
netali kinsane
'eu vi o caba vermelha'
netali
'eu o(caba vermelha) vi'
kihleri kinsane
'caba vermelho bonito'
tsrili kinsane
'caba vermelho grande'
mtseriti kinsane
'caba vermelho pequeno'
sati kinsane
'uma caba vermelha'

Já a caba estrela é do gênero feminino. 


$\begin{array}{ll}\text { d) klatasonulo } & \text { 'caba estrela' } \\ \text { netalo klatasonulo } & \text { 'eu vi o caba estrela' } \\ \text { netali } & \text { 'eu o(caba estrela) vi' } \\ \text { kihlero klatasonulo } & \text { 'caba estrela bonito' } \\ \text { tsrolo klatasonulo } & \text { 'caba estrela grande' } \\ \text { mtseroto klatasonulo } & \text { 'caba estrela pequeno' } \\ \text { sato klatasonulo } & \text { 'um caba estrela' }\end{array}$

Elementos da natureza são, em princípio, masculinos.

$\begin{array}{ll}\text { 6) kasireri } & \text { 'folha' } \\ \text { netali kasireri } & \text { 'eu vi o folha' } \\ \text { netali } & \text { 'eu o (folha) vi' } \\ \text { kihleri kasireri } & \text { 'folha bonito' } \\ \text { tsrili kasireri } & \text { 'folha grande' } \\ \text { mtseriti kasireri } & \text { 'caba pequeno' } \\ \text { poaloli kasireri } & \text { 'folha amarela' } \\ \text { poleri kasireri } & \text { 'folha verde' } \\ \text { sati kasireri } & \text { 'uma folha' } \\ \text { hepi kasireri } & \text { 'duas folhas' } \\ \text { mapa kasireri } & \text { 'três folhas' }\end{array}$

A lontra vai à água, mas não vive na água, portanto é masculino. Ilopo 'cajá' só dá frutos na época da chuva, por isso é feminino. Da mesma forma tolokana 'cerejeira', pau de fazer canoa, é feminino, como a própria canoa. Iopo 'mogno' é feminino, pois o nambu que vive nos baixos do rio e nas beiras das lagoas sempre faz o seu ninho no tronco dela. Kanika 'cacau' é feminino, pois 'sobe-se o barranco do rio para colher seus frutos'. Usini 'samaúma' é feminino, pois quando está perto de chover flora, além do que cresce principalmente nos baixos do rio.

Outros nomes femininos são sipri 'tracajá', Jima 'peixe', kupaçi 'lambari', iotlo 'caranguejo', tlolo 'sapo', jawo 'bicho preguiça', speri 'açaí', seropirofa 'sororoca d'água', hijçipifa 'tipo de cipó', ksatiçci 'areia do rio', kanawa 'canoa', naçtimta 'pulseira', naft $i$ ' colar', tsapiçt $f i$ 'cinto'.

Outros nomes masculinos são mhenokli 'onça', çema 'anta', t fkootu 'macaco prego', tkat $/ i$ 'sol', hipowhafa 'lagoa', weno 'rio', ksiri 'lua', sotli 'pedra, himriçi 'morro', tfiçi 'terra', hokani 'cachoeira', konri 'seringueira', 
katfirali 'flecha', himati 'panela', salohapi 'remo', tsapatfi 'bolsa', fetfi 'rede', tfipriri 'bem-te-vi', Jwejli 'beija flor'.

\subsection{A explicação do gênero pelos mitos}

Há vários casos em que a explicação para a atribuição de gênero é encontrada nos mitos. Um deles é o gênero feminino do pássaro caboré. $\mathrm{O}$ mito conta que havia um menino muito bonito, chamado Poerono katu. Antes ele era perebento e sua cunhada tinha nojo de lhe dar tepaliha 'caiçuma', pahoya 'na cuia'. Passava que ele fingia ser doente, mas, na realidade, ele era um homem sagrado e muito bonito. Então um dia a mãe ficou com vergonha da nora dele e fingiu passar o leite de pioçi 'leite da guariúba' (masculino). Aí um dia ele saiu todo pintadinho, com a kofma 'kusma', então ela, a cunhada, se interessou por ele. Então ele falou: "Você não achava eu feio, todo perebento?" Mas ela aperreou tanto ele para fazer sexo com ela que ele deu um susto nela; e os passarinhos carregaram ela para longe. $\mathrm{O}$ irmão ficou brabo com ele e pediu para ele fosse atrás dela. E disse: "Já que você fez ela ir embora, você agora tem que buscá-la de volta! Mas os passarinhos a haviam colocado na casa de João de Barro (pitsiwa masc.). Aí quando ele foi atrás da cunhada, ele a achou, mas deu um sopro nela e disse que as novas gerações irias chamá-la de mosa 'caboré' (pássaro que anda de noite). Ele não trouxe mais ela de volta e, com vergonha do irmão dele virou beija-flor e ela continuou caboré. Daí porque o pássaro caboré é do sexo feminino, porque resultou da transformação de uma mulher.

A atribuição do gênero feminino ao caboré, o qual deveria, em princípio, pertencer ao gênero masculino, parece corresponder ao que Dixton (1982:179) chamou de myth-and-belief principle, em que:

If some noun has characteristic $X$ (on the basis of which its class membership is expected to be decided) but is, through belief or myth, connected with characteristic $\mathrm{Y}$, then generally it will belong to the class corresponding to $\mathrm{Y}$ and not that corresponding to $\mathrm{X}$.

Outro caso análogo ao do caboré é do ksakçert 'traíra', que é masculino, mesmo sendo da água, porque virou çpiro 'calango', que por sua vez é masculino. Por outro lado, o calango, é feminino, porque se transformou em traíra, que é da água. A atribuição de gênero aqui é a imagem inversa do gênero original dos animais que sofreram essa transformação.

\section{Atribuição de gênero a empréstimos culturais}

Em Manxineru, elementos culturais emprestados são associados ao gênero feminino, como são os casos dos exemplos seguintes:
a) celular 'celular'
netalo celular
'eu vi o celular' 


$\begin{array}{ll}\text { netalo } & \text { 'eu o (celular) vi' } \\ \text { kihlero celular } & \text { 'celular bonito' } \\ \text { tsroto celular } & \text { 'celular pequeno' } \\ \text { mtseroto celular } & \text { 'celular grande' } \\ \text { ksaçiro celular } & \text { 'celular preto' } \\ \text { klatalo celular } & \text { 'celular branco' } \\ \text { serolo celular } & \text { 'celular vermelho' } \\ \text { polero celular } & \text { 'celular verde' } \\ \text { pwalolo celular } & \text { 'celular amarelo' } \\ \text { sato celular } & \text { 'um celular' } \\ & \\ \text { b) televisão } & \text { 'televisão' } \\ \text { netalo televisão } & \text { 'eu vi a televisão' } \\ \text { netalo } & \text { 'eu a (televisão) vi' } \\ \text { kihlero televisão } & \text { 'televisão bonita' } \\ \text { tsroto televisão } & \text { 'televisão pequena' } \\ \text { mtseroto televisão } & \text { 'televisão grande' } \\ \text { ksaçiro televisão } & \text { 'televisão preta' } \\ \text { klatalo televisão } & \text { 'televisão branca' } \\ \text { serolo televisão } & \text { 'televisão vermelha' } \\ \text { polero televisão } & \text { 'televisão verde' } \\ \text { pwalolo televisão } & \text { 'televisão amarela' } \\ \text { sato televisão } & \text { 'uma televisão' }\end{array}$

O Manxineru é, portanto, uma língua em que o gênero padrão é o gênero feminino.

\section{Algumas considerações finais}

Os dados apresentados neste estudo mostram que, diferentemente do que descrevem trabalhos anteriores sobre o Manxineru por Matteson (1965) e por Hanson (2010), a categoria de gênero é semanticamente transparente e culturalmente motivada nessa língua. Seres humanos e determinados animais concebidos como possuidores de sexo, nomes que referem estágios de existência de humanos e nomes de parentesco apresentam uma clara distinção de gênero biologicamente motivada. Já os referentes dos demais nomes são, em princípio, masculinos, se não aquáticos, e femininos, se aquáticos ou a estes relacionados. 
Trata-se, portanto, de atribuição de gênero culturalmente orientada, motivada. E como demonstra Lakoff (1987:582) "The concept of motivation is needed in order to account for a great many of the regularities that occur in grammar." E, em Manxineru, é a motivação cultural que explica, entre outras coisas que certos seres aquáticos são considerados masculinos. Serão masculinos se suas atitudes, características comportamentais, por exemplo, se associam a atitudes dos machos. Da mesma forma, um animal da terra pode ser feminino se possui habilidades, atitudes e outras características femininas, sendo, assim, comparável a fêmeas e classificado como 'feminino'.

Um fato importante que mostramos nesse estudo é o de que o gênero de certos animais só encontram uma explicação nos mitos, em um tempo em que se passava naturalmente de um estado de ineri humanidade a um estado de heçnine animalidade, ou de um estado animal a outro.

Há, entretanto, casos em que não há uma explicação plausível para justificar a classificação de certos referentes de nomes em masculino ou feminino. Mas em todo sistema classificatório de nomes semanticamente motivados, há exceções, devido a mudanças fonológicas, morfológicas ou de extensões semânticas, contato, por exemplo, ocorridas na história das línguas.

Há também casos em que o gênero se manifesta nos nomes em uma modalidade, mas a concordância se faz por meio de outro gênero. Estes e outros aspectos do sistema de gênero em Manxineru carecem de mais estudos. O fundamental aqui são os dados reunidos que mostram ser a classificação dos referentes de nomes Manxineru em masculinos ou femininos motivada, semântica e culturalmente, e estabelecida por meio de processos predominantemente metafóricos.

\section{Referências}

Aikhenvald, Alexandra Y. 2000. Classifiers: A typology of noun categorization devices. Oxford: Oxford University Press.

Borges, M. V. 1997. As falas feminina e masculina no Karajá. Goiânia: Universidade Federal de Goiás, Dissertação de Mestrado.

Campbell, Lyle. 2012. Typological characteristics of South American indigenous languages. The Indigenous Languages of South America: A Comprehensive Guide, ed. by Lyle Campbell and Verónica Grondona, 259-330. Berlin: Mouton de Gruyter.

Campbell, Lyle. 2012. Language contact and linguistic change in the Chaco. RBLA 5(2):255-287.

Dixon, R. M. W. 1982. Where Have All the Adjectives Gone? Berlin: Walter de Gruyter.

Dixon e Akhenvald. 1999. The Amazonian Languages. Cambridge: Cambridge University Press.

Drude, S. 2002. Fala masculina e feminina em Awetí. In A. D. Rodrigues, \& A. S. A. C. Cabral (Eds.), Línguas indígenas Brasileiras: Fonologia, gramática e história. (Atas do I Encontro Internacional do Grupo de Trabalho sobre Línguas Indígenas da 
ANPOLL). vol. 1 (pp. 177-190). Belém: EDUFPA.

Facundes, Sidney da S. 2000. The Language of the Apurinã People of Brazil. Tese de Ph.D., SUNY-Búfalo: Búfalo.

Lakoff, G. 1987. Women, Fire, and Dangerous Things. University of Chicago Press.

Monserrat, Ruth M. F. 2000a. Características lexicais e morfológicas da fala masculina e feminina na língua Aweti. (MS)

Monserrat, Ruth M. F. 2000b. Prefixos pessoais em Awetý, Série Linguística III, Museu Nacional.

Ramirez, Henri. 2001. Uma gramática do Baníwa do Içana. (MS).

Ribeiro, E. R. 2012. A grammar of Karajá. Ph.D dissertation, University of Chicago.

Rodrigues, A. D. 2004. Sobre a possível origem da diferença fonética entre a fala masculina e a feminina em Karajá. Liames 4:115-121. Campinas, SP, UNICAMP.

Tovar, Antonio. 1961. Catálogo de las lenguas de América del Sur. Buenos Aires: Editorial Sudamericana.

Data recebimento: $20 / 01 / 2015$

Data aceite: $15 / 04 / 2015$ 